\title{
The scalable solution to recycling of end of life (EOL) printed wiring boards (PWBs)
}

\author{
T. Chen ${ }^{1}$, P. Jiang ${ }^{2}$, M. A. Harney ${ }^{1}$, G. M. L. Lazarus ${ }^{1}$, B. Chen ${ }^{2}$, \\ Y. Song ${ }^{2}$, H. Chen ${ }^{2}$, G. L. Serke ${ }^{1}$, G. M. Rose ${ }^{1} \&$ M. B. Korzenski ${ }^{1}$ \\ ${ }^{1}$ Chief Technology Office, Advanced Technology Materials Inc., USA \\ ${ }^{2}$ Chief Technology Office, \\ Advanced Technology Materials Inc., P.R. China
}

\begin{abstract}
With $<2 \%$ of the mass in US landfills, electronic waste (e-waste) accounts for $70 \%$ of hazardous materials. Approximately 5\% by weight of e-waste consists of valuable secondary resource stock-printed wiring boards (PWBs). Those PWBs with high metal value are sold to overseas smelters and those PWBs with low value are sent to Asia or Africa where the integrated circuits (ICs) are manually desoldered and the trace precious metals are collected either by open burning or from chemical leaching with toxic chemicals such as hot aqua-regia and cyanide, which lead to environmental pollution and human exposure to hazardous chemicals. This paper reports novel cradle-to-cradle PWBs recycling processes and enhanced process efficiencies based on green chemistry and green engineering methodologies for the complete recycling of PWBs. We will describe that one can recover metals and valuable components from end-of-life (EOL) PWBs using cost effective, sustainable, and scalable methods. This includes both chemical desoldering and precious metal reclaim on ATMI's eVOLV $^{\mathrm{TM}}$ PWBs recycling line.
\end{abstract}

Keywords: WEEE, e-waste, EOL, PWBs, green chemistry, green engineering, desoldering, gold leaching, ICs, recycling, valuable metals.

\section{Introduction}

Globally more than 50 million metric tons of waste from electrical and electronic equipment (WEEE), also known as electronic waste (e-waste) was disposed of in 2009 according to Zeller's [1] and Cobbing's reports [2]. This is expected to 
grow to over 72 million metric tons by 2014 . However less than $20 \%$ of all ewaste is recycled with the majority ending up in developing countries such as China, India, and Brazil. For example, a study by Bastiann et al. [3] in 2005 shows that the total supply of e-waste in the US was up to 6.6 million metric tons of which 20\% was exported to Asia. Among all ten categories of WEEE listed in the Directive 2002/96/EC of the European Union (EU) [4], the volume of the end of life (EOL) printed wiring boards (PWBs) in electronics such as personal computers, mobile devices etc. grows exponentially due to the accelerated replacement of these IT and telecommunication equipment driven by the technical innovation and market expansion. As a matter of fact, the number of personal computer in use around the world, which is a major source of scrapped PWBs, has surpassed 1 billion in 2008, and they would become obsolete by 2013. Thus how to deal with EOL PWBs presents an ever growing waste management problem to the governments, the general public and companies.

Currently the main options for hierarchy management of e-waste including highly valuable EOL PWBs are reuse, remanufacturing and recycling as well as incineration and landfilling. However the incineration of EOL PWBs by traditional methods for municipal solid waste is dangerous. For example, copper in the laminated fiber glass composites based substrates of PWBs with embed flame-retardants is a catalyst for dioxin formation when they are incinerated. This is of particular concern for the incineration of brominated flame retardants such as polybrominated diphenyl ethers (PBDEs) at low temperature. To make things worse, it was estimated that emissions from incineration of certain components in e-waste such as integrated circuits (ICs), capacitors, liquid crystal displays and batteries on EOL PWBs, accounts for 36 metric tons per year of mercury and 16 metric tons per year of cadmium in the EU Community [5].

In the meantime, the last place for these EOL PWBs is a landfill because of the valuable resources in them such as metals (copper, nickel, lead, tin, gold, silver, platinum, and palladium) that could be recycled and reused. For example, it has been reported by Cui et al. that the values of copper, silver, and gold alone make up $>80 \%$ of the total value for most EOL PWBs, which is also confirmed by our own assay analyses. Sulliven [7] reported one ton of used mobile phones ( 6000 handsets - a small fraction of the nearly 1 billion annual production) contains $340 \mathrm{~g}$ of gold, $3.5 \mathrm{~kg}$ of silver, $140 \mathrm{~g}$ of palladium and $130 \mathrm{~kg}$ of copper with a combined value of $\$ 28,000$ ( $\sim 2.5$ billion total). Global revenues for e-waste recovery are expected to grow to $\$ 14.6$ billion by 2014 according to Zeller [1]. In addition, while $<2 \%$ of the mass in US landfills, e-waste accounts for $70 \%$ of the heavy metals pollution [8]. And there are adverse environmental impacts of those heavy metals such as lead and mercury in landfills. As a result, a national e-waste strategy was unveiled in US this year that promotes environmentally friendly management of used electronics [9].

There is a general three-step process of recovering the valuable metals in PWBs described by Cui and Roven [6], step 1 - disassembly: a selective disassembly by sorting out both hazardous and valuable components is performed here, step 2 - upgrading: either mechanical processing and/or metallurgical processing is applied to prepare the sorted PWBs for the final 
refining processes. Step 3 - refining: recovered metals from steps 1 and 2 are melted or dissolved and separated by using metallurgical and chemical techniques, including pyrometallurgical and hydrometallurgical processing. In step 2, mechanical processing such as comminution of EOL PWBs is environmentally friendly except for the potential particular hazards. However its major drawback is the poor recovery of valuable metals in a later refining process (step 3) due to the loss of them during the size reduction step in such a comminution step reported by Ogunniyi and Vermaak [10]. While in step 3, pyrometallurgical process including incineration, smelting in a plasma arc furnace or blast furnace, dross formation, sintering, melting, and reactions in a gas phase at high temperatures arc are commonly applied to both the whole feed stream undergoing minimum mechanical processing or crushed EOL PWBs. However the hazard of releasing toxic furans, dioxins, and noxious gases to the environment is severe and the handling/abatement of the gaseous pollutants is expensive. As compared with pyrometallurgical processing, the hydrometallurgical method is more exact, more predictable, and more easily controlled. As a result, hydrometallurgical processes have been developed in the past two decades and become a very attractive process for recovery of metals from EOL PWBs as reported by Gloe et al. [11] and Ogata and Nakano [12]. However, standard hydrometallurgical processes dissolve all components in, for example, a strong acid and then selectively remove the specific elements of interest. While the dissolution step is simple, selectively removing each component from the mixture in high yield is a complex and time consuming challenge. In addition, numerous studies have been carried out to evaluate the exposure of toxic substances from some informal recycling activities in developing countries, such as China, India, and Nigeria. The level of toxins such as acids released using environmentally unfriendly chemicals in such a hydrometallurgical process is very high in some informal recycling activities. For example, e-waste recycling in Guiyu, China, has been reported by Guo et al. [13] to result in the contamination of the entire region, pervading the water, air, soil, and biota of the region.

Alternatively in a hydrometallurgical process, one may use more complex chemical formulations to selectively dissolve individual metals from EOL PWBs and ICs thereby simplifying the overall recycling process in both steps 2 and 3 mentioned above. Building on its 25-year knowledge-base of developing chemistries for the fabrication of semiconductors, ATMI has been using the principles of Green Chemistry and Green Engineering pioneered by Anastas and Warner [14] and Anastas and Zimmerman [15] on both silicon wafer reclaim reported by Korzenski and Jiang [16] and in-line cleaning of immersion lithography tools reported by Chen et al. [17]. We recently have demonstrated a proprietary all wet cleantech solution $-\mathrm{eVOLV}^{\mathrm{TM}}[18]$ to retrieve ICs that could be reused or further recycled and to extract surface gold from selectively dissembled EOL PWBs in a safe, environmentally sound and economic manner. A schematic diagram of the process is shown in fig. 1. EOL PWBs pass on a conveyer system from a desoldering module to a gold leaching module or vice versa. ICs are collected and clean boards emerge at the end of process line. In the 
meantime, all of the chemistry and the rinse water are recycled for reuse in the process. Note that no mechanical processing such as commonly used shredding or grinding is required in ATMI's PWBs recycling process which may lead to the loss of up to $40 \%$ of precious metals and/or to the formation of dangerous metal fines, dust containing brominated flame retardants, and dioxins.

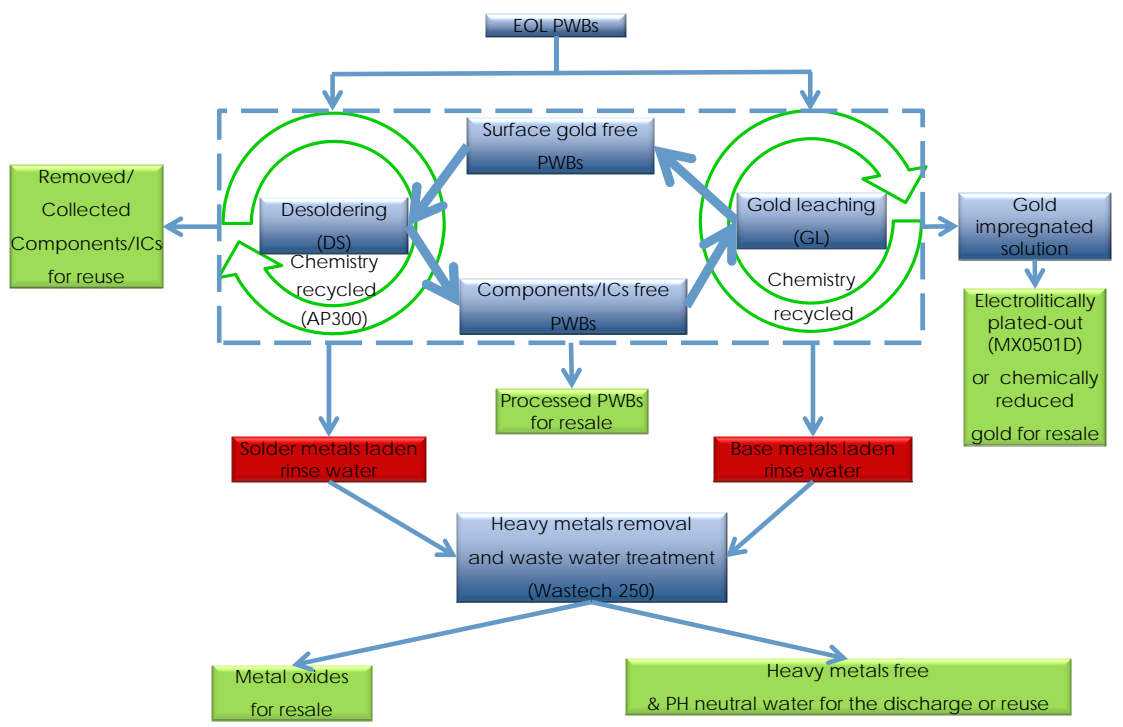

Figure 1: The process flow of ATMI's PWBs recycling technology (the process flow on eVOLV ${ }^{\mathrm{TM}}$ PWBs recycling line is in the dottedline box, all outputs/value streams are in green).

\section{Experimental section}

\subsection{Materials and chemicals}

The EOL PWBs samples were purchased or collected from certified e-waste recyclers in the US. Nitric acid, hydrochloric acid were purchased from Aldrich and used as received. All the EOL PWBs were processed either on the ATMI's $\mathrm{eVOLV}^{\mathrm{TM}}$ PWBs recycling line (fig. 2) or in beakers.

The gold impregnated gold leaching (GL) solution was electrolytically deposited on a 3D carbon cathode on a MX0501D plating tool from Renovare international Inc. (fig. 3). The free acids in ATMI's proprietary desoldering (DS) chemistry can be reclaimed on AP300 from MechChem associates Inc. (fig. 3). The solder/heavy metals laden solutions were treated on WasTech250 system from WasTech Controls and Engineering Inc. (fig. 3). 


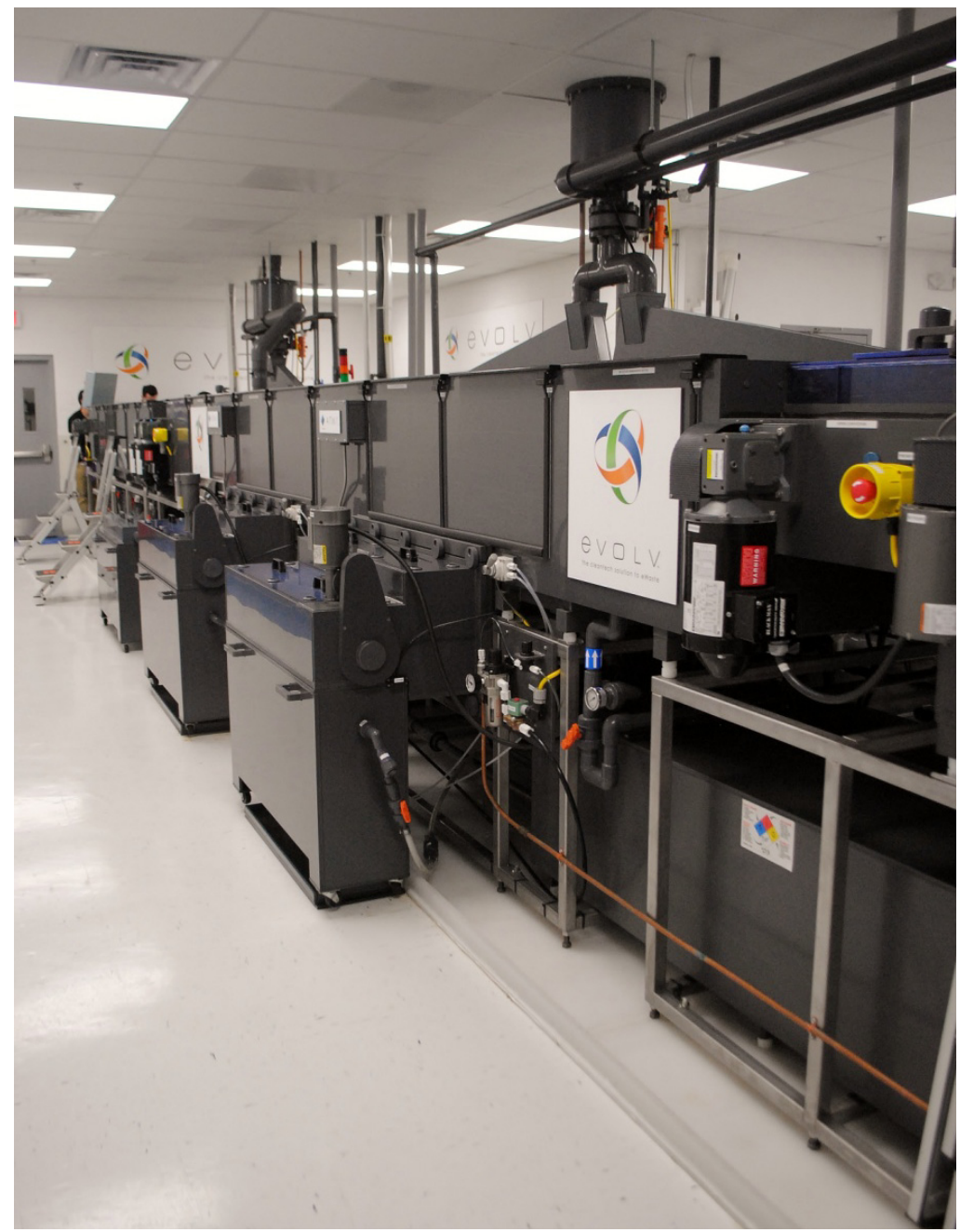

Figure 2: $\quad$ The front view of ATMI's eVOLV ${ }^{\mathrm{TM}}$ PWBs recycling line.

\subsection{Samples preparations and metrologies}

To prepare powder samples for the assay experiments, components such as capacitors, liquid crystal displays, and batteries on PWBs which are usually rich in hazardous substances were first removed from the boards before comminution in SM 200 and ZM 300 from Retsch consecutively.

The thickness of immersion gold layers on the surface of EOL PWBs was measured on a Rigaku ZSX 400 WDXRF (Wavelength dispersive X-ray fluorescence) spectrometer. The concentrations of metals ions (Ag, $\mathrm{Au}, \mathrm{Cu}, \mathrm{Ni}$, $\mathrm{Pb}, \mathrm{Sn}, \mathrm{Pd}, \mathrm{Pt}, \mathrm{Fe}$ and $\mathrm{Zn}$ ) in solution were measured on a PerkinElmer Optima 5300DV ICP-OES (Inductively coupled plasma atomic emission spectroscopy) 
instrument. The concentrations of anions in ATMI's proprietary DS and GL formulations were measured either on a Dionex ICS-2100 ion chromatography instrument or a CARY $50 \mathrm{UV}$-Vis spectrometer from Varian.
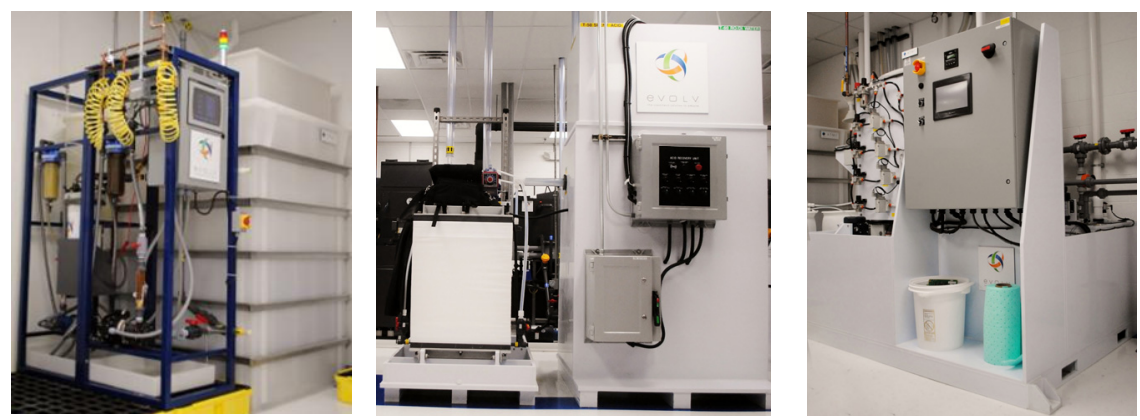

Figure 3: From left to right: the front view of the electroplating tool MX0501D, the front view of 2 modules of the acids reclaim tool AP300 and the front view a module of the heavy metals removal and waste water treatment tool - WasTech 250.

\section{Results and discussion}

\subsection{Desoldering step of ATMI's EOL PWBs recycling process}

All ICs and components (capacitors, resistors, heat sinks, connectors, etc.) on asreceived $\mathrm{PWBs}$ are chemically desoldered in two consecutive desolder modules on ATMI's eVOLV ${ }^{\mathrm{TM}}$ PWBs recycling line. This step requires less than 20 minutes immersion of EOL PWBs such as RAM (random access memory) boards, PCI (peripheral component interconnect) video cards, hard drives in an acidic solution at a temperature between 30 and $40{ }^{\circ} \mathrm{C}$. The solid outputs of this step are components free PWBs and removed components including fully functional ICs.

ATMI's proprietary DS chemistry is highly selective towards both $\mathrm{Pb} / \mathrm{Sn}$ and $\mathrm{Sn} /$ Ag solders while leaving copper, gold, etc. on the board and other base metal components intact. Note in fig. 4 that the gold connectors and even the stickers on sample B after the DS step remain intact on the board visually. Further comparison between the measured thickness of gold layers between as-received sample A and desoldered sample B using XRF in fig. 5 shows no measurable difference, demonstrating the good selectivity of the DS chemistry towards different valuable metals. This is highly advantageous as compared to commonly used hot aqua regia in traditional hydrometallurgical processes because the absence of solder metals after ATMI's DS process (fig. 1) in the previous metals refining process simplifies the recovery efforts and increases the resale values of processed components and solders free PWBs. At the same time, ATMI's DS process also reduces any potential human exposure towards toxic $\mathrm{Pb}$ containing 


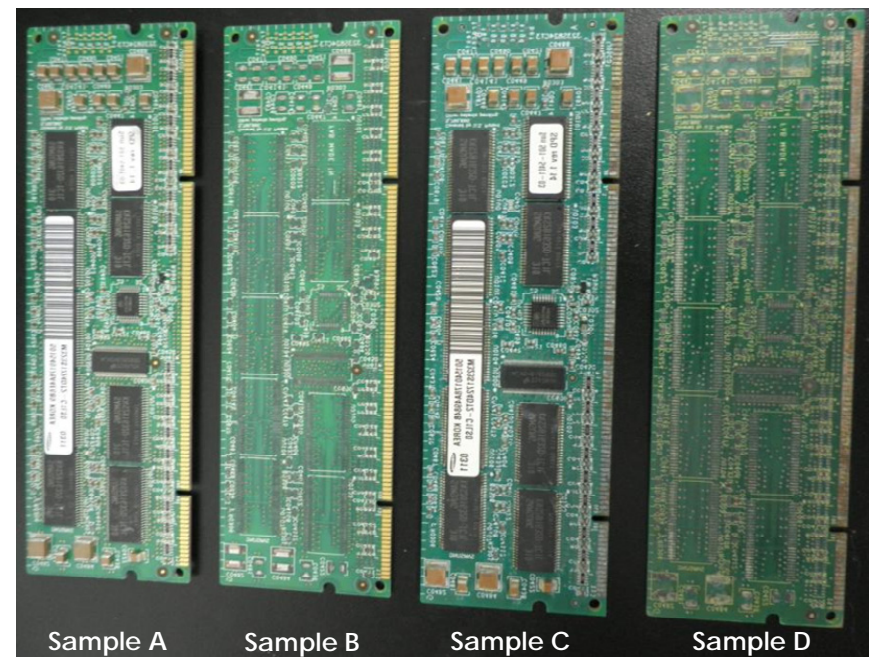

Figure 4: Pictures of RAM boards processed on ATMI's eVOLV ${ }^{\mathrm{TM}}$ PWBs recycling line: A. As-received boards, B. desoldered boards (the removed components are not included), C. surface gold leached boards, D. desoldered and surface gold leached boards (the removed components are not included).
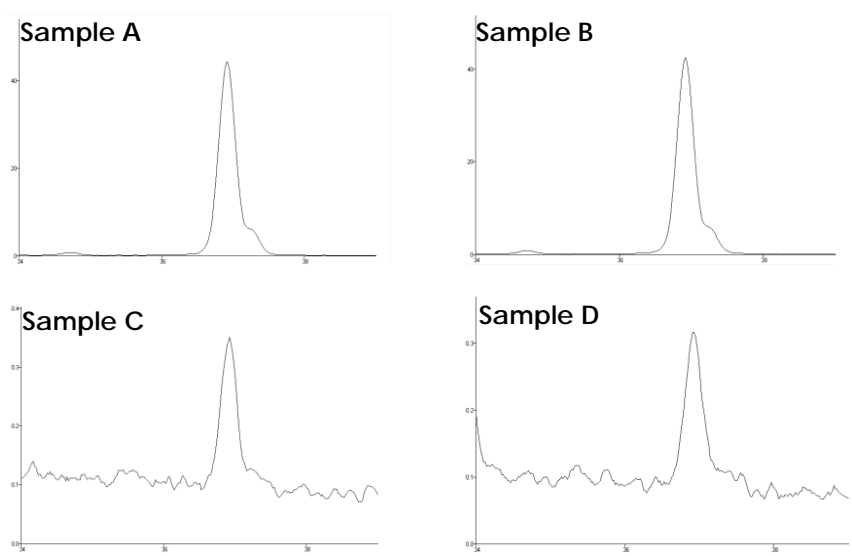

Figure 5: The XRF spectra of surface gold on RAM boards processed on ATMI's eVOLV ${ }^{\mathrm{TM}}$ PWBs recycling line (Au peak intensities in counts vs. $2 \theta$ in degree): A. As-received boards, B. desoldered boards, C. surface gold leached boards, D. desoldered and surface gold leached boards. 
species during processing as compared to pyrometallurgical approaches in traditional refining process. The removed solder materials, mainly $\mathrm{Pb} / \mathrm{Sn}$ alloys, is dissolved in ATMI's proprietary DS chemistry first before being converted and collected as a metal oxide salt on the heavy metals removal and waste water treatment tool WasTech 250 and resold.

The bath of ATMI's proprietary DS chemistry can be monitored using both ICP-OES and IC techniques in real time until it is loaded to over $250 \mathrm{~g}$ per liter. Furthermore, both DS chemistry and the rinse water are recycled multiple times (fig. 1). The electrical tests of the desoldered chips by a third party institute show that they are still operational and thus may be reused. Given that manufacturing a single $2 \mathrm{~g}$ chip uses $1.6 \mathrm{~kg}$ of fossil fuels, $72 \mathrm{~g}$ of chemicals, $32 \mathrm{~kg}$ of water and $700 \mathrm{~g}$ of gases reported by Williams et al. [19], this is a tremendous environmental and economic savings.

\subsection{Gold leaching step of ATMI's EOL PWBs recycling process}

The now solder-free components-free PWBs after the desoldering process are subjected to a non-toxic, environmentally benign ATMI's proprietary GL chemistry in the GL module on ATMI's eVOLV ${ }^{\mathrm{TM}}$ PWBs recycling line at $30^{\circ} \mathrm{C}$ for approximately 5-10 min (depending on composition and thickness of surface gold), which selectively removes all gold together with other precious metals such as silver, palladium, etc. Visually sample D in fig 4 is a components/ICs free, surface gold free bare board. The $>98 \%$ leaching efficiency of gold in this gold leaching step is further verified by the dramatic difference between the measured thickness of gold layers between as-received sample A and gold leached samples C and D using XRF shown in fig. 5. It is clear that there is little to no gold residue on the surface of PWBs after the gold leaching process on ATMI's eVOLV ${ }^{\mathrm{TM}} \mathrm{PWBs}$ recycling line, which is further confirmed by little detected gold in ICP-OES measurements of the same type of gold leached PWBs digested in hot aqua regia. Furthermore, the good selectivity of ATMI's proprietary GL chemistry over solder and other base metals is manifested by the components/ICs intact sample $C$ that underwent gold leaching process only and visible nickel/copper underlayers on both samples $\mathrm{C}$ and $\mathrm{D}$ in fig. 4. This merit of GL chemistry allows flexible and modulated desoldering and gold leaching process flows on ATMI's eVOLV ${ }^{\mathrm{TM}} \mathrm{PWBs}$ recycling line despite of the process sequence shown in fig. 1 . The bath life of this chemistry can also be monitored by UV-Vis technique while the dissolved gold in ATMI's proprietary GL chemistry can be monitored by ICP-OES technique in real time and eventually be reclaimed electrolytically on MX0501D (fig. 3) or hydrometallurgically via a chemical reduction process demonstrated at a bench scale before being sold for its value.

Alternatively, the ICs collected after ATMI's desoldering process may be ground and the trace precious metals, mainly gold, are extracted using ATMI's proprietary GL chemistry in the GL module on ATMI's eVOLV ${ }^{\mathrm{TM}}$ PWBs recycling line mentioned above.

After rinsing, the clean printed wiring boards may be chopped and the copper collected and sold. We have demonstrated $>99 \%$ copper recovery with $>99.5 \%$ 
purity, which have also been confirmed by an independent testing laboratory. Because no solder or base metals are present, the value of these processed PWBs is very high. The remaining chopped fiberglass may be used as filler in, for example, cement.

\section{Summary}

The entire PWBs recycling process flow in fig. 1 has been validated by reclaiming metals and components/ICs from several tons of EOL PWBs (TV, computer, cell phone, etc.) on ATMI's eVOLV ${ }^{\mathrm{TM}}$ PWBs recycling line that is closed so that no volatiles escape (fig. 2). This pilot system has been scaled to handle up to 250 lbs per hour of high value PWBs (RAM boards, PCI video cards, hard drives, CPUs (central processing units)) and all of the chemistry is recycled for reuse in the process. This system is being used to further optimize both the chemistry and the process flow for a wider range of PWBs and to refine the process economic models. Water discharged from ATMI's eVOLV ${ }^{\mathrm{TM}}$ PWBs recycling line is treated on WasTech 250, has less than part-per-million trace metals and no organics. It fully meets the discharge criteria from Connecticut department of energy and environment protection in the US (table 1) and can potentially be reused in the PWBs recycling process.

Table 1: $\quad$ The PHs and trace metal concentrations in two different streams of rinse water from ATMI's eVOLV ${ }^{\mathrm{TM}}$ PWBs recycling line before and after the treatment on WasTech 250.

\begin{tabular}{|c|c|c|c|c|c|c|c|c|c|c|c|c|c|c|c|c|c|}
\hline \multirow{3}{*}{$\begin{array}{c}\text { The type of the } \\
\text { waste water }\end{array}$} & \multirow{3}{*}{$\begin{array}{c}\text { The volume of the } \\
\text { waste water } \\
\text { (gallons) }\end{array}$} & \multicolumn{8}{|c|}{ Before the treatment } & \multicolumn{8}{|c|}{ Before the final discharge } \\
\hline & & \multirow[b]{2}{*}{ PH } & \multicolumn{7}{|c|}{ Trace metals (ppm) } & \multirow[b]{2}{*}{ PH } & \multicolumn{7}{|c|}{ Trace metals (ppm) } \\
\hline & & & $\mathrm{Ag}$ & $\mathrm{Cu}$ & $\mathrm{Fe}$ & $\mathrm{Ni}$ & $\mathrm{Pb}$ & Sn & $\mathrm{Zn}$ & & $\mathrm{Ag}$ & $\mathrm{Cu}$ & $\mathrm{Fe}$ & $\mathrm{Ni}$ & $\mathrm{Pb}$ & Sn & $\mathrm{Zn}$ \\
\hline DS rinse water & 200 & 2.6 & 0 & 0.3 & 1.4 & 0.6 & 1.3 & 0.1 & 0.1 & 8.6 & 0 & 0 & 0.2 & 0 & 0 & 0 & 0 \\
\hline GL rinse water & 200 & 1.44 & 0.09 & 2.3 & 18 & 80 & 2.8 & 2.5 & 1.3 & 9 & 0.1 & 0 & 0 & 0.8 & 0 & 0 & 0 \\
\hline
\end{tabular}

\section{Acknowledgements}

We thank Dr Larry Dubois at ATMI for useful discussions, Guangcai Mark Wang at ATMI for the assistance of the procurement of EOL PWBs, Jessica Broccoli for the build-up of formulation scale-up unit/transfer pumps and Dr Jun-fei Zheng at ATMI for XRF measurements.

\section{References}

[1] Zeller, T., A Program to Certify Electronic Waste Recycling Rivals an Industry - U.S. Plan, New York Times, April 15, 2010.

[2] Cobbing, M., Not in Our Backyard. Uncovering the Hidden Flows of eWaste, Report from Greenpeace International, http://www.greenpeace.org/ international/en/publications/reports, 2008. 
[3] Bastiaan, C., Zoeteman, J., Krikke, H.R. and Venselaar, J., Handling WEEE waste flows: on the effectiveness of producer responsibility in a globalizing world, International Journal of Advanced Manufacturing Technology 47, 415-436, 2010.

[4] European Parliament and the Council of the European Union, Directive 2002/96/EC of the European Parliament and of the Council of 27 January 2003 on waste electrical and electronic equipment (WEEE), Official Journal of the European Union, L37, 24-38, 2003.

[5] Draft proposal for a European Parliament and Council directive on waste electrical and electronic equipment, European Commission Report Brussels, 2000.

[6] Cui, J., and Roven, H. J. Electronic waste, From Waste: A Handbook for Management, eds. Letcher, T. M., Vallero, D. A., pp. 281-296, 2011.

[7] Sullivan, D.E., Recycled Cell Phones - A Treasure Trove of Valuable Metals, http://pubs.usgs.gov/fs/2006/3097/fs2006-3097.pdf.

[8] Computers, E-Waste, and Product Stewardship: Is California Ready for the Challenge, Report for the US Environmental Protection Agency, Region IX, pp. 13, May 11, 2001.

[9] Mukhopadhyay, R., National e-waste strategy unveiled, Chemical and Engineering News, 89, pp. 28, 2011.

[10] Ogunniyi, I.O., and Vermaak, M.K.G., 2007. Improving printed circuit board physical processing - an overview, Proceedings of European Metallurgical Conference, Dusseldorf, Germany, pp. 1645-1656, June 1114, 2007.

[11] Gloe, K., Muhl, P. and Knothe, M., Recovery of Precious Metals from Electronic Scrap, in Particular from Waste Products of the Thick-Layer Technique, Hydrometallurgy 25, 99-110, 1990.

[12] Ogata, T., and Nakano, Y., Mechanisms of gold recovery from aqueous solutions using a novel tannin gel adsorbent synthesized from natural condensed tannin, Water Research, 39, 4281-4286, 2005.

[13] Guo, Y., Huang, C.J., Zhang, H., and Dong, Q. X., Heavy Metal Contamination from Electronic Waste Recycling at Guiyu Southeastern China, Journal of Environmental Quality, 2009.

[14] Anastas, P., and Warner, J. C., Green Chemistry: Theory and Practice; Oxford University Press Inc., New York 1998.

[15] Anastas, P., and Zimmerman, J., Env. Sci. and Tech. 37, 94, 2003.

[16] Korzenski, M., and Jiang, P., Wafer reclaim, Handbook of cleaning for semiconductor manufacturing, eds. Reinhardt, K. A., and Reidy, R. F., pp. 473-499, 2011.

[17] Chen, T., Korzenski, M. B., Bilodeau, S., Zhang, P., Hogan, T., van Berkel, K., Mirth, G., Mih, R., Hoekerd, K., Jansen, B., Vangheluwe, R., and Schuh, N, Environmentally benign in-line cleaning solutions for immersion lithography tools, Solid State Phenomena, 187, pp. 307-310, 2012.

[18] Korzenski, M. B., Jiang, P., Norman, J., Warner, J., Ingalls, L., Gnanamgari, D., Strickler, F., and Mendum, T., Sustainable process for 
reclaiming precious metals and base metals from electronic waste, PCT Int. Appl. WO2012024603, 2012.

[19] Williams, E. D., Ayres, R. U. and Heller, M., The 1.7 Kilogram Microchip: Energy and Material Use in the Production of Semiconductor Devices, Environ. Sci. Technol. 36, pp. 5504-5510, 2002. 